\title{
Photobiomodulation and Mandibular Advancement Modulates Cartilage Thickness and Matrix Deposition in the Mandibular Condyle
}

\author{
Wanessa Ferreira Franco, MSc, ${ }^{1}$ Marcos Vinicios Borges Galdino, BSc, ${ }^{2}$ Lucas Raineri Capeletti, DDS, \\ Bárbara Helena Sberowsky, DDS, Renan Araújo Vieira, DDS, ${ }^{1}$ Augusto César Figueiredo, PhD, \\ Karen Müller Ramalho, $\mathrm{PhD},{ }^{3}$ Fernanda Cristina Alcântara dos Santos, $\mathrm{PhD}$, \\ Manoel Francisco Biancardi, PhD, ${ }^{2}$ Paulo de Marco, Jr., PhD, ${ }^{4}$ and Mara Rubia Marques, $\mathrm{PhD}^{2}$
}

\begin{abstract}
Objective: We evaluated the effects of photobiomodulation (PBM), mandibular advancement (MA), and the combination of both treatments (PBM+MA) on condylar growth, by the analysis of cartilage and bone formation, fibrillar collagen deposition, proteoglycan content, cell proliferation, and clastic cell index (CCI). Methods: Forty male Wistar rats were randomly assigned to CONTROL, PBM, positive control-MA, and PBM+MA groups. The appliance was worn $10 \mathrm{~h} /$ day. Laser was irradiated bilaterally on mandibular condyles in 8 alternate days ( 1 irradiation point per condyle) using the following parameters: $780 \mathrm{~nm}, 10 \mathrm{~J} / \mathrm{cm}^{2}, 40 \mathrm{~mW}$, $1 \mathrm{~W} / \mathrm{cm}^{2}, 10 \mathrm{sec} /$ point, $0.4 \mathrm{~J} /$ point, and cumulative dose per point: $3.2 \mathrm{~J}$. PBM+MA received both treatments simultaneously. After 15 days, the animals were euthanized and the condyles dissected and embedded in paraffin. Histological sections from the intermediate portion of the condyle were used for morphometric analysis. The relative frequency $(\%)$ of fibrillar collagens was determined in sections stained with picrosirius red-hematoxylin under polarized light or Gömöri's method for reticular fibers. Proteoglycan content was evaluated by computerized photocolorimetric analysis. CCI was determined by tartrate-resistant acid phosphatase (TRAP), and proliferating cell nuclear antigen (PCNA) was detected by immunohistochemistry.

Results: PBM and MA influenced condylar cartilage thickeness and matrix deposition, but none of the treatments affected significantly the area of the condyle. CCI were not influenced by the treatments, but clastic cells distribution was influenced by MA and PBM+MA treatments. There was no significant difference in proliferating cells among the groups.

Conclusions: This study demonstrated that PBM and MA stimulates matrix deposition and cartilage thickening in the mandibular condyle, but was not able to demonstrate a synergistic effect between the treatments. Additional studies should be conducted to evaluate the possible synergistic effect between PBM and MA.
\end{abstract}

Keywords: cartilage, bone, mandibular condyle, collagen, low-level laser therapy, mandibular advancement

\section{Introduction}

$\mathbf{G}$ ROWTH DISCREPANCIES BETWEEN the maxilla and the mandible characterize most of the malocclusions and can cause overload in the temporomandibular joint (TMJ) and disturbances in the physiology of the stomatognathic system. ${ }^{1}$ In growing patients, functional devices for man- dibular advancement (MA) are used in the management of class II malocclusion and have shown to effectively reduce growth discrepancies between the maxilla and mandible. ${ }^{2}$ These devices transfer tensions to the mandibular condyle, modulating cartilage growth and bone formation. ${ }^{3}$ The effects are increased cell proliferation, ${ }^{4}$ growth factor expression, and matrix deposition, ${ }^{5-7}$ besides apoptosis regulation. ${ }^{8}$

\footnotetext{
${ }^{1}$ Dental School, Federal University of Goiás, Goiânia, Brazil.

${ }^{2}$ Biological Sciences Institute, Department of Histology, Embryology and Cell Biology, Federal University of Goiás, Goiânia, Brazil. ${ }^{3}$ Dental School, Ibirapuera University, São Paulo, Brazil.

${ }^{4}$ Biological Sciences Institute, Department of Ecology, Federal University of Goiás, Goiânia, Brazil.
} 
The mandibular condyle is the main growth center of the mandible and is lined by a secondary cartilage. Its superior layers comprise the fibrous layer, which is composed of a rich collagen I matrix and of an undifferentiated layer, whose cells can differentiate into cartilage or bone, depending on the nature of the stimulus affecting the tissue. ${ }^{9}$ Following the undifferentiated layer, there are the chondroblast layer, the chondrocyte layer, the hypertrophic layer, and the degenerative layer. ${ }^{6}$ In this study, we refer to the last four layers as maturation zone.

The possibility of modulating condylar growth is the key to achieve efficient approaches for the treatment of malocclusion. The combination of features capable of potentiating the known effects of functional devices or shortening the period of treatment is desirable, and studies involving photobiological stimuli have yielded promising results. ${ }^{10,11}$

Photobiomodulation (PBM) has been used in dentistry for the past 30 decades due to its analgesic, anti-inflammatory, and biostimulatory effects. ${ }^{12-14}$ Many studies on the treatment of oral disorders such as herpes labialis, mucositis, stomatitis, and temporomandibular disorders have indicated these positive properties of PBM. ${ }^{15-18}$ The effects of PBM on the tissues are based on its interaction with the mitochondrial membranes, stimulating energy production. ${ }^{19}$ In the joint cartilage, PBM enhances the stiffness of the repairing tissue, ${ }^{20}$ and increases extracellular matrix volume ${ }^{21}$ and the production of glycosaminoglycans and collagen II. ${ }^{22}$

This study tested the hypothesis that PBM could improve MA effects on cartilage and bone tissues of the mandibular condyle.

\section{Materials and Methods}

\section{Animals and experimental protocol}

All experiments were conducted in accordance with the guidelines of the Committee on Animal Experimentation of the Federal University of Goiás (CEUA/UFG 154/2009). Forty 30-day-old (juvenile phase) male Wistar rats were provided by the UFG's central animal facility and maintained in the vivarium of the Laboratory of Morphology at $22^{\circ} \mathrm{C}$ in a $12 \mathrm{~h} / 12 \mathrm{~h}$ light/dark cycle. Animals received water and food ad libitum (Labina-Purina ${ }^{\circledR}$ ) during the adaptation period, but during the experimental period, animals received food only in the dark period to prevent the removal of the mandibular appliance. The animals were randomly assigned to four groups ( $n=10$ /group): intact control, PBM, positive control$\mathrm{MA}$, and PBM and MA combined (PBM+MA), the lattern of which was patented by the Federal University of Goiás (BR102016018828-8). MA was performed by a propulsive appliance designed as described by Hajjar et al. ${ }^{6}$ The appliance was used from 8:00 a.m. to 6:00 p.m., totaling $10 \mathrm{~h}$ daily in both positive control-MA and PBM+MA groups (Fig. 1A). In brief, the appliance consists of a copper plate fixed in the upper incisors of the animals. It creates an inclined plane, in which the mandible is displaced anteriorly every time the animal closes its mouth, following the principles of functional orthopedics. The animals wore a soft leather collar to prevent the removal of the appliances (Fig. 1B, C).

\section{Photobiomodulation}

A continuous-wave laser diode (InGaAlP; Twin Laser; MM Optics ${ }^{\circledR}$, São Carlos, Brazil) was used. A power meter

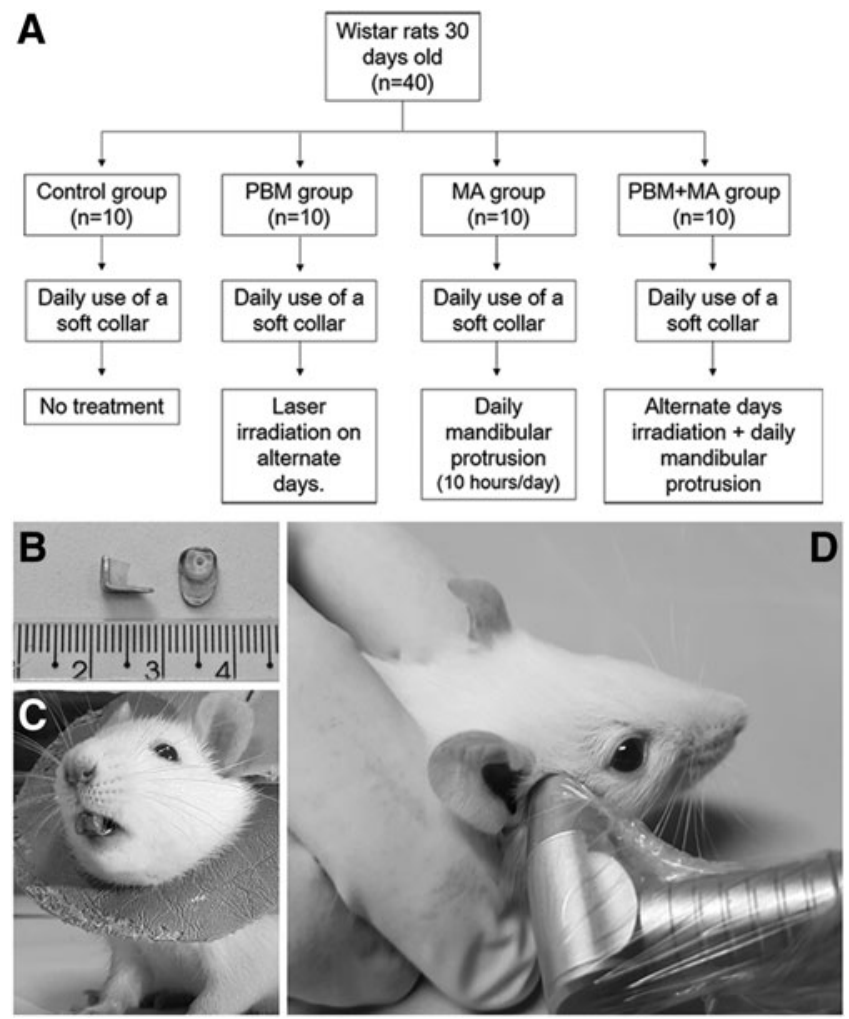

FIG. 1. Experimental design. (A) Diagram representing the study recruitment. (B) Superior and lateral view of the functional appliance for MA. (C) Functional appliance installed in rat upper incisors. Note the soft leather collar. (D) Laser irradiation in the TMJ region. The leather collar was removed for a better view. MA, mandibular advancement; TMJ, temporomandibular joint.

(Laser Check; MM Optics, São Carlos, Brazil) was used to determine the laser output power before each irradiation. The parameters used are based on previous studies ${ }^{28}$ and were as the following: wavelength: $780 \mathrm{~nm}$; power output: $40 \mathrm{~mW}$; spot size: $0.04 \mathrm{~cm}^{2}$; power density: $1 \mathrm{~W} / \mathrm{cm}^{2}$; energy density: $10 \mathrm{~J} / \mathrm{cm}^{2}$; one point of irradiation for each TMJ; energy/point: $0.4 \mathrm{~J}$; and duration of irradiation: $10 \mathrm{sec} /$ point. As laser applications were performed for 8 alternate days, then the total accumulated energy per point was $3.2 \mathrm{~J}$ (Table 1). Irradiation was applied to one point covering the TMJ region, bilaterally, and the laser beam was applied in contact with the skin at an angle of $90^{\circ}$ (Fig. 1D). Irradiation was performed every other day, at 3:00 p.m. During the study, the animals were weighed every other day.

\section{Histological processing}

After 15 days of treatment, the animals were euthanized (ketamine $180 \mathrm{mg} / \mathrm{kg}$ of body weight combined with xylazine $20 \mathrm{mg} / \mathrm{kg}$ of body weight). The condyles were fixed in methacarn solution for $3 \mathrm{~h}$, demineralized in 5\% EDTA solution, and processed for Paraplast ${ }^{\circledR}$ embedding (Sigma Chem. Co., St Louis, MO). Serial sagittal sections $(5 \mu \mathrm{m})$ from the intermediate portion of the condyles were used for analysis.

\section{Morphometric analysis}

The sections were stained with hematoxylin-eosin (HE) and then analyzed and photographed using a Primo Star 
Table 1. Laser Parameters

\begin{tabular}{cccccc}
\hline Irradiance $\left(\mathrm{W} / \mathrm{cm}^{2}\right)$ & Dose $\left(\mathrm{J} / \mathrm{cm}^{2}\right)$ & $\begin{array}{c}\text { Duration of } \\
\text { irradiation }(\mathrm{sec})\end{array}$ & $\begin{array}{c}\text { Frequency of } \\
\text { treatment }\end{array}$ & $\begin{array}{c}\text { Cumulative dose } \\
\text { per point }(\mathrm{J})\end{array}$ & $\begin{array}{c}\text { Cumulative dose } \\
\left(\mathrm{J} / \mathrm{cm}^{2}\right)\end{array}$ \\
\hline 1 & 10 & 10 & 8 Alternate days & 3.2 & 80 \\
$\begin{array}{l}\text { Wavelength }(\mathrm{nm}) \\
780\end{array}$ & $\begin{array}{c}\text { Power output }(\mathrm{mW}) \\
40\end{array}$ & $\begin{array}{c}\text { Spot size }\left(\mathrm{cm}^{2}\right) \\
0.04\end{array}$ & $\begin{array}{c}\text { Points/irradiation }(\mathrm{n}) \\
1\end{array}$ & $\begin{array}{c}\text { Energy per point }(\mathrm{J}) \\
0.4\end{array}$ & \\
\hline
\end{tabular}

iLed microscope (Carl Zeiss MicroImaging, Goettinger, Germany) attached to an AxioCam ERc 5s microcamera (Carl Zeiss MicroImaging, Jena, Germany). Measurements ( $n=4$ animals/group) were performed using Image Pro-Plus 6.0 (Media Cybernetics, Inc., Silver Spring, MD). The area per section of the cartilage, bone, and the whole section of the condyle was determined from the intermediate portion of the condyles at $100 \times$ magnification. To determine the thickness of the layers five sections per animal were photographed at $400 \times$ magnification. In each of them, 5 linear measurements were obtained, totaling 100 measurements for each layer per group.

\section{Distribution and relative frequency of fibrillar collagens}

Sections were stained with picrosirius red-hematoxylin and then analyzed and digitized using a Zeiss Axioscope A1 light microscope (Zeiss) with polarizing filter $(n=4$ animals/group). Collagen III (reticular fibers) was detected by Gömöri's silver impregnation technique. Fifteen microscopic fields were obtained from the undifferentiated layer and also from the maturation zone $(1000 \times$ magnification $)$ per animal, totaling 60 fields/group. The relative frequency of fibrillar collagens was obtained using Weibel's ${ }^{23}$ multipurpose test grid with 130 points and 10 test lines. The relative value was determined by counting the coincident points in the test grid and dividing them by the total number of points using the Image-Pro Plus software v6.1 for Windows (Media Cybernetics, Inc.).

\section{Determination of proteoglicans content}

The content of proteoglycan was determined by computerized photocolorimetric analysis and the variable of interest was optical density. For that, 400-fold increased images obtained in light field microscopy were used to determine the optical density in the ImageJ software (National Institute of Health) using the pluggin Fiji. A circular macro was used to capture the optical density at 3 distinct points of each image, totaling 108 points of quantification per group. The intensity of staining was quantified on a scale between 0 and 255, with 0 being the highest density and 255 being the lowest.

\section{Clastic cell index}

The clastic cell index (CCI) per area was determined in the posterior region of the condyle using tartrate-resistant acid phosphatase (TRAP) 387 kit (Sigma-Aldrich, St Louis, $\mathrm{MO})$ according to the manufacturer's instructions. Four sections of the intermediate portion of the condyle were used per animal. Two images from the subchondral zone were obtained for each region of the condyle, totaling eight images per region. Images were captured at $400 \times$ magnification comprising an area of $5590 \mathrm{~mm}^{2}$. The number of clastic cells was counted in the subchondral zone $(n=6$ animals/group and 36 fields/animal) using Image Pro-Plus 6.0 (Media Cybernetics, Inc.).

\section{Immunohistochemistry}

Tissue sections were subjected to immunohistochemistry for detection of the proliferating cell nuclear antigen (PCNA; $n=6$ animals/group). The sections were deparaffinized, rehydrated through a decreasing ethanol series, and the Leica BIOSYSTEMS NovoLink Polymer Detection System Kit (RE7150-K) was used according to the manufacturer's instructions. DAB was used as chromogen.

\section{PCNA quantification}

Seventy-two microscopic fields ( $n=6$ animals/group; $40 \times$ magnification) were used for PCNA quantification in each experimental group. In each field, the total number of positive cells was obtained as relative frequency (\%) in relationship to the total number of cells. All the analyses were performed using the previously described image analysis system.

\section{Statistical analysis}

The proper evaluation of the existence of a synergistic effect between PBM and MA demands the evaluation of the statistical interaction of them. Otherwise, as different measurements in the same individual are not statistically independent, we include the individual as a random effect in all analysis. Thus, we apply a General Linear Mixed Model (GLMM) to the results using the package LME4 in the software $\mathrm{R}^{24}$ This choice favored both the use of all information collected, respect the statistical independence, and increase statistical power of the test. GLMM is known to have a higher statistical power even under small sample sizes since it can consider the repeated measurements in each individual in the analysis. ${ }^{25}$ Values are presented as mean \pm standard error of mean. Statistical data not present in the main text are available in the Supplementary Tables S1-S4.

\section{Results}

\section{Morphometric analysis}

None of the treatments increased significantly the area of the condyle, neither the cartilage nor bone areas (Fig. 2AC). In the condylar cartilage, none of the treatments changed the fibrous layer thickness (Fig. 3A). The undifferentiated layer and the maturation zone were increased by PBM and 
by MA. However, there was no synergistic effect between the treatments in these layers (Fig. 3B, C).

\section{Distribution and relative frequency of fibrillar collagens}

In the control and PBM groups, fibrillar collagens were oriented predominantly on the long axis of the undifferentiated layer (Fig. 4 a, b). In the MA and PBM+MA groups, fibrillar collagens were clearly oriented in the posterosuperior direction; however, fibers were thicker in the PBM+MA group (Fig. 4c, ). In the maturation zone, fibrillar collagens were located around the chondrocyte lacunae and were progressively thicker in the treated groups (Fig. $4 \mathrm{e}-\mathrm{h}$ ). PBM decreased the percent of fibrillary collagens in the undifferentiated layer (Fig. 4i) and increased it in the maturation zone (Fig. 4j). MA increased fibrillar collagens in the undifferentiated layer (Fig. 4i) and in the maturation zone (Fig. 4j). Collagen III was present in the undifferentiated layer and its relative frequency increased in all the groups, particularly in the PBM group (Fig. 5A). There was no synergistic effect between the treatments on fibrillar collagen deposition.

\section{Distribution and optical density of proteoglicans}

Proteoglicans depositon was detected in the maturation zone. According to the scale of the Fiji pluggin of the ImageJ program, the higher the number of proteoglycans, the lower the value attributed to optical density. So, the content of proteoglycan in the CONTROL group (167.2 \pm 1.4$)$ was lower than the treated groups $(\mathrm{PBM}=153.2 \pm 1.4$; positive control-MA $=144.8 \pm 1.6$ and $\mathrm{PBM}+\mathrm{MA}=141.8 \pm 1.0 ; p \leq$ $0.05)$. However, there was no synergistic effect between the treatments (Fig. 5B-E).

\section{Cell proliferation}

PCNA-stained cells were distributed in the chondroblast and hypertrophic layers of the condylar cartilage in all groups. The relative frequency (\%) of PCNA-positive cells did not differ significantly among the groups despite the increase in PBM and positive control-MA groups (Table 2).

\section{Clastic cell index}

The histochemical analysis of TRAP revealed a similar pattern for TRAP-positive clastic cells in all groups. Numer- ous multinucleated TRAP-positive clastic cells were attached to the trabeculae in the subchondral region of the condyle, which is characteristic of active clastic cells. Cell count revealed no statistical difference among the groups (Table 2).

\section{Discussion}

This study tested the hypothesis that PBM could improve the effects of MA on condylar growth. Therefore, the effects of MA, PBM, and PBM+MA on the morphology of bone and cartilage of the mandibular condyle were assessed after 15 days of treatment. The relative frequency (\%) of proliferating cells and fibrillar collagens in the cartilage was also evaluated. The CCI was determined for the subchondral zone in the anterior, central, and posterior regions of the condyle. MA was performed $10 \mathrm{~h}$ daily and the total laser energy applied was $3.2 \mathrm{~J}$.

The treatments affected neither the area of the condyle nor the area of the cartilage or the bone, however, the effect of PBM varied in the different layers of the condylar cartilage. PBM did not affect the fibrous layer, reduced the undifferentiated layer, and increased the maturation zone, suggesting that the effects of PBM depend on the characteristics or the sensitivity of the tissue to photobiological stimuli. PBM reduced the undifferentiated layer thickness. This effect is contrary to bone growth once the more the undifferentiated cells, the more the bone formation in the mandibular condyle. ${ }^{4}$ However, even though PBM reduced the undifferentiated layer, it increased the maturation zone thickness and matrix deposition in this layer. These results suggest an inductive effect on cell differentiation. Such stimulatory effect has been previously shown by in vitro studies on cartilage, ${ }^{21}$ osteocytes, ${ }^{26}$ and cardiomyocytes. ${ }^{27}$ In other words, PBM does not seem to be able to promote condylar cartilage growth, but it prepares the tissue for bone formation, at least in the evaluated period. Fekrazad et al. ${ }^{28}$ described similar effects on joint cartilage defects in rabbits, showing that PBM does not increase cartilage but promotes bone formation. Long-term studies could demonstrate whether PBM consolidates bone formation in the mandibular condyle.

Sinergistic effects of PBM associated to MA on bone formation have been demonstrated by morphometric ${ }^{29,30}$ and cephalometric studies. ${ }^{31,32}$ Our study did not show significant increase in the bone area for any of the
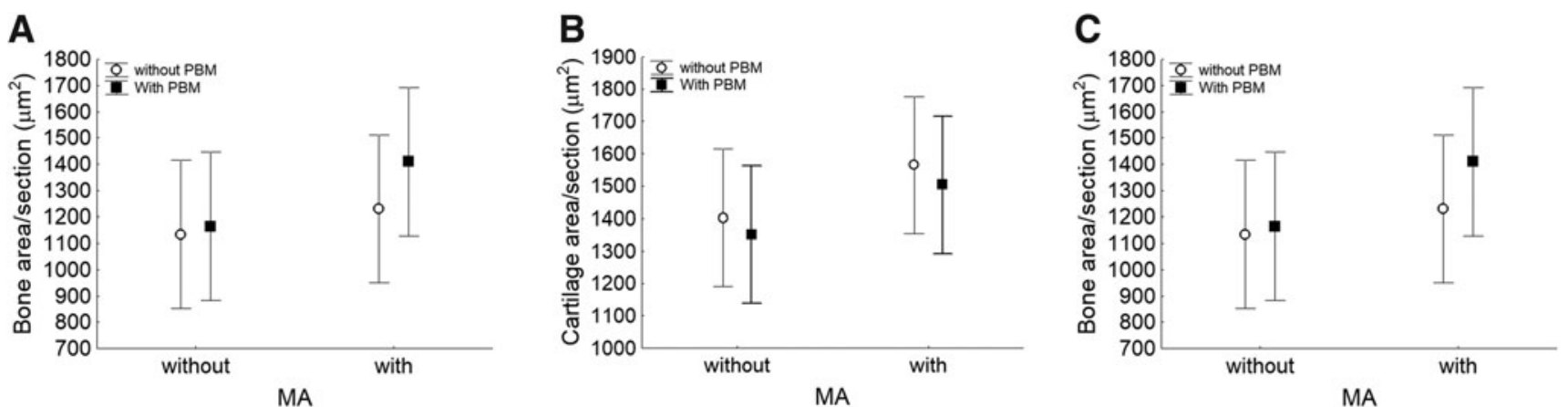

FIG. 2. Area per section in the mandibular condyle. Area per section considering the whole condyle (A), condylar cartilage (B), or bone (C). PBM or MA did not affect the area of the condyle. Neither the area of cartilage nor the area of bone was affected by the treatments. GLMM, $p<0.05$. GLMM, General Linear Mixed Model; PBM, photobiomodulation. 
A

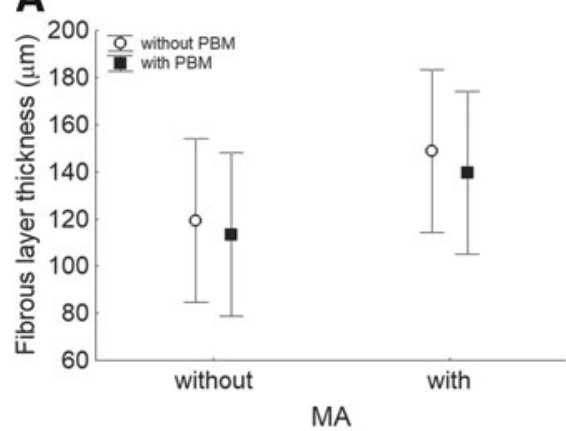

B

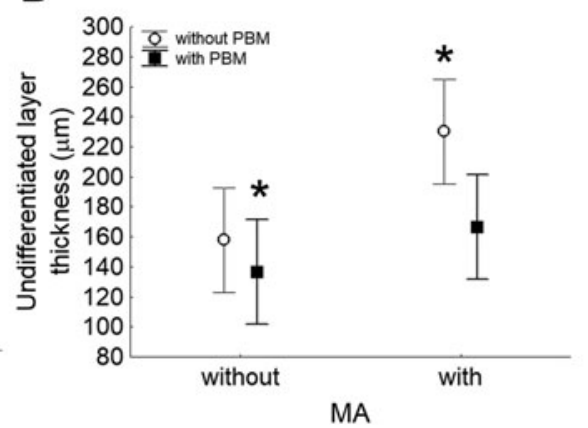

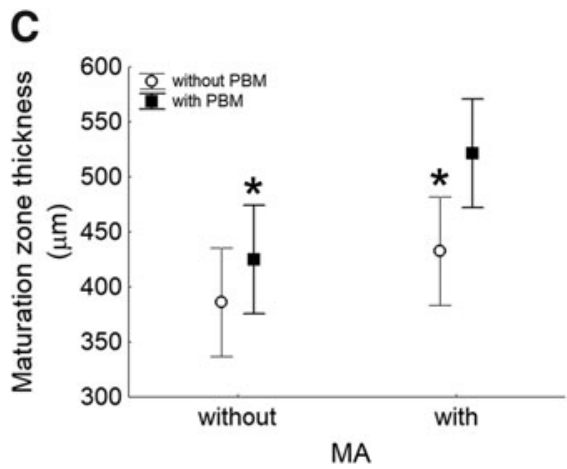

FIG. 3. Thickness of the condylar cartilage layers. Fibrous layer (A), undifferentiated layer (B), and maturation zone (C). PBM and MA modulated the thickness of the condylar cartilage. However, there was no synergic effect between the treatments. *Indicates statistical significance. GLMM, $p<0.05$.

treatments, however, PBM and MA increased cartilage thickness in the undifferentiated layer and in the maturation zone. There is a close relationship between the amount of extracellular matrix in the hypertrophic layer and the potential amount of bone formation. ${ }^{20,21}$ All the treatments increased the maturation zone thickness, which involves the hypertrophic layer. PCNA-stained cells and fibrillar collagens also increased in the hypertrophic layer of the PBM and positive control-MA groups; however, as the increase in PCNA-stained cells was not statistically significant, we

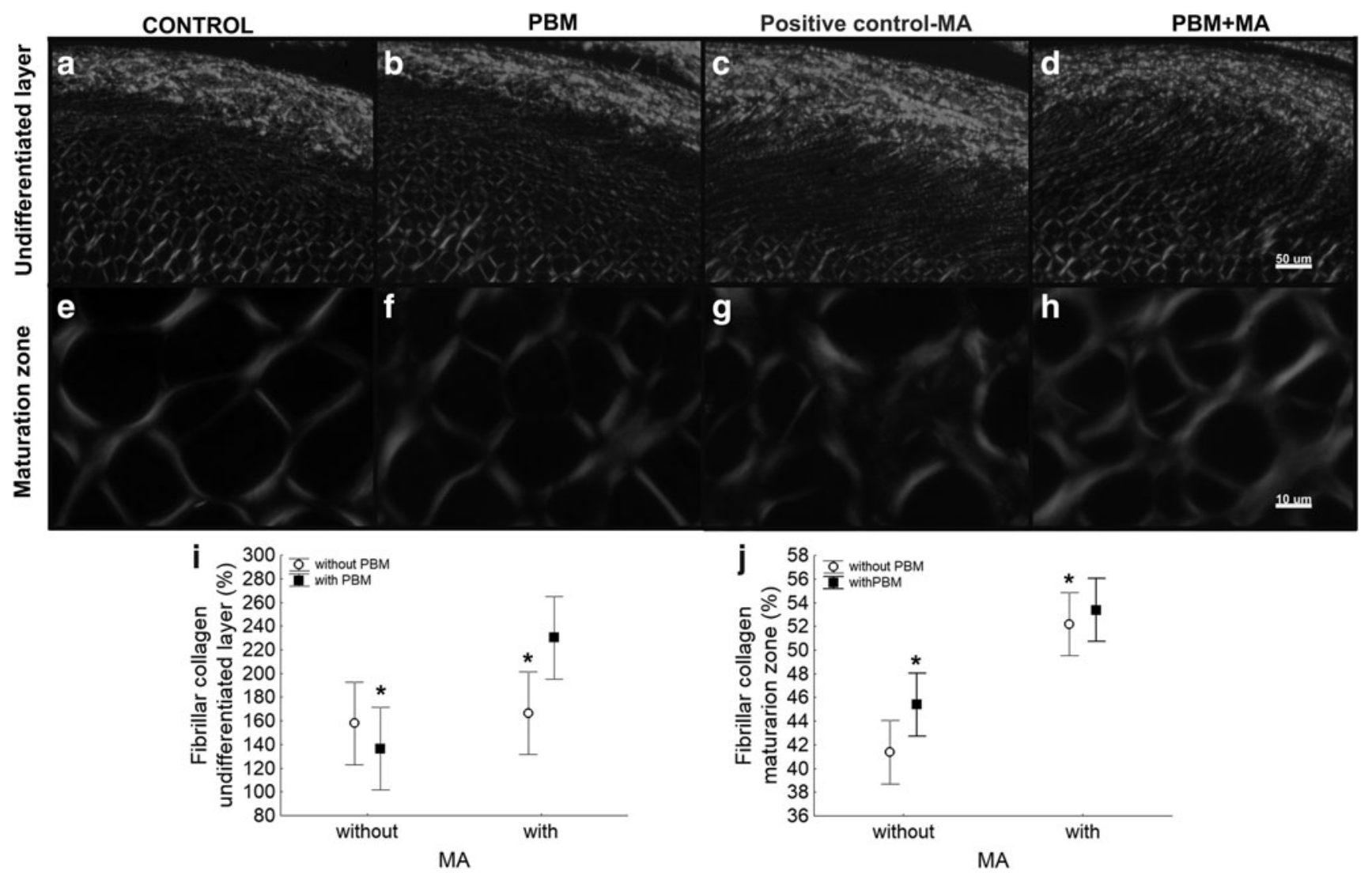

FIG. 4. Fibrillar collagens in the posterior region of the condylar cartilage. Picrosirius red staining shows fibrillar collagens in the fibrous layer and undifferentiated layers $(\mathbf{a}-\mathbf{d})$, and in the maturation zone (e-h) of the condylar cartilage. Note fibrillar collagens in the undifferentiated layer lining the condyle in the control (a) and PBM (b) groups. In the positive control-MA (c) and PBM+MA (d) groups, the undifferentiated layer became thicker and fibers were oriented toward the posterosuperior direction. In the maturation zone, collagen was located around the chondrocyte lacunae. Note that fibers thicken progressively in the treatment groups compared with the control $(\mathbf{e}-\mathbf{h})$. In the undifferentiated layer, the relative frequency (\%) of fibrillar collagens decreased in the PBM group and increased in MA and PBM+MA groups (i). In the maturation zone, the percent of fibrillar collagens increased in all treated groups (j). There was no synergic effect between the treatments for fibrillar collagen deposition. *Indicates statistical significance. GLMM, $p<0.05$. 


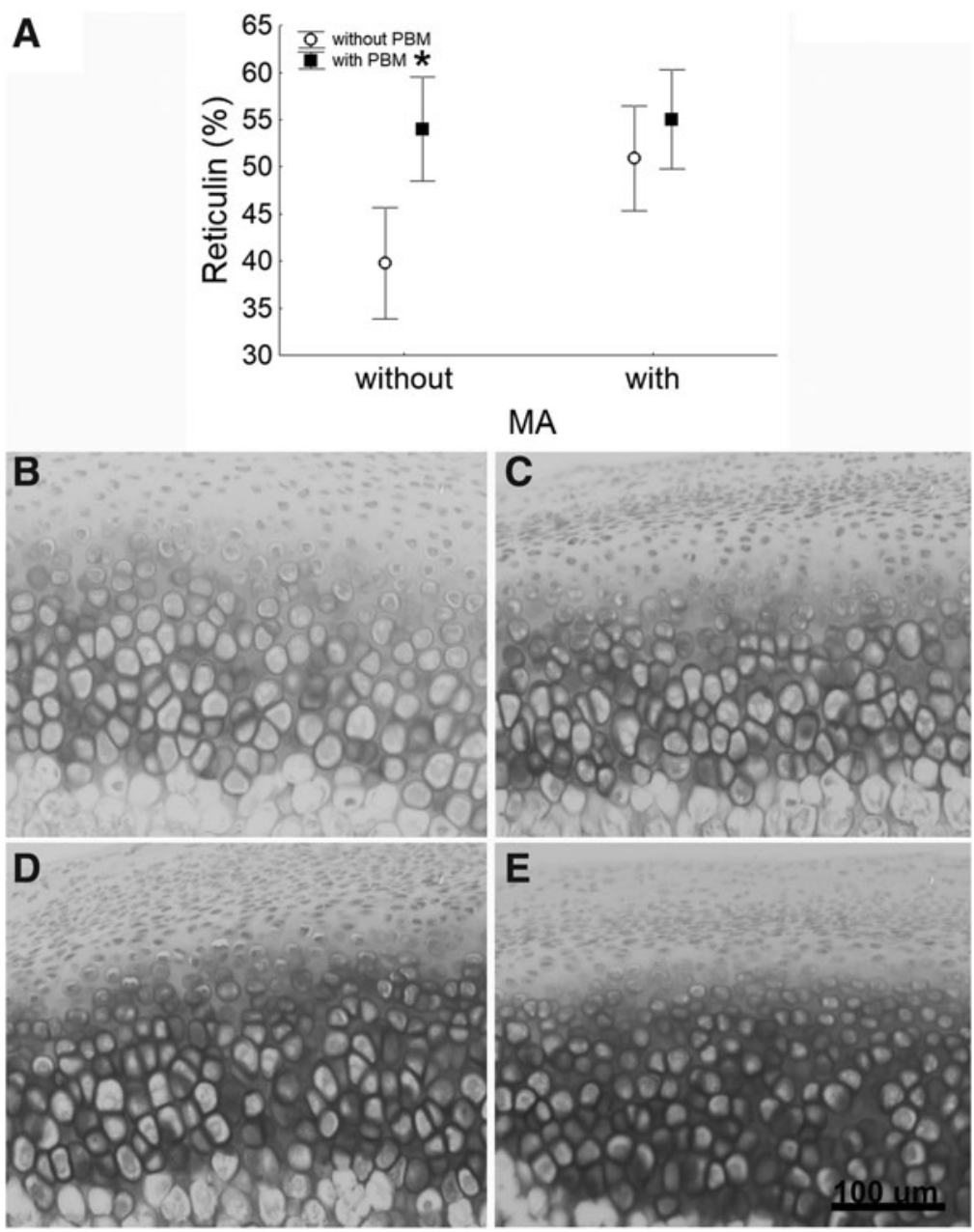

FIG. 5. Reticulin (collagen III) and proteoglycan deposition in the condylar cartilage. Relative frequency of collagen III (A) and proteoglycan depositon (B-E) increased in all the treated groups, however, there was no synergistic effect between the treatments. *Indicates statistical significance. GLMM, $p<0.05$. considered the increase in the maturation zone to be closely related to fibrillar collagen production. These findings are in line with the literature, showing an increase of collagen $X$ in the hypertrophic layer after 14 days of mandibular protrusion. $^{22}$ The proteoglycan content also increased in all the treated groups, certainly contributing to the maturation zone increase.

According to Shen et al., ${ }^{21}$ it is well established that postnatal growth of the mandibular condyle is mainly supported by endochondral ossification of the condylar cartilage. The condyle is the main growth center of the mandible; thus, modulating its bone formation is important to adjust

Table 2. Proliferation and Clastic Cells Index in the Condylar Cartilage

\begin{tabular}{lccccc}
\hline & \multicolumn{2}{c}{ PCNA } & & \multicolumn{2}{c}{ CCI } \\
\cline { 2 - 3 } \cline { 5 - 6 } Groups & Chi-square & $\mathrm{p}$ & & Chi-square & $\mathrm{p}$ \\
\hline PBM & 1.43 & 0.23 & & 0.26 & 0.60 \\
MA & 0.00 & 0.97 & & 0.17 & 0.67 \\
PBM+MA & 2.03 & 0.15 & & 0.00 & 0.95 \\
\hline
\end{tabular}

GLMM, $p<0.05$.

CCI, clastic cell index; GLMM, General Linear Mixed Model; MA, mandibular advancement; PBM, photobiomodulation; PCNA, proliferating cell nuclear antigen. the growth discrepancies between the maxilla and the mandible. Combining MA with PBM may offer a new possibility of treatment for class II malocclusion.

Few studies have evaluated the thickness of condylar cartilage layers. Abtahi et al. ${ }^{29}$ using $1.8 \mathrm{~J} /$ point, $5.4 \mathrm{~J} / \mathrm{d}$, and $113.40 \mathrm{~J}$ of energy accumulated after 3 weeks of daily application compared MA and PBM+MA groups and found that condylar cartilage thickness remained unchanged between the groups and reduced the fibrous layer in the PBM+MA group. Previous studies conducted at our laboratory ${ }^{30}$ applying $0.4 \mathrm{~J} /$ point, one point per condyle/day, and $3.2 \mathrm{~J}$ of energy accumulated after eight intercalated applications are partially at odds with these findings, showing that $\mathrm{PBM}+\mathrm{MA}$ increased total cartilage thickness when compared to the MA group. ${ }^{30}$ Now, in the present study, we suggest that the total increase in cartilage thickness could be promoted by collagen and proteoglican deposition in the maturation zone.

In the undifferentiated layer of the positive control-MA and PBM+MA groups, collagen fibers became backwardoriented, corroborating the data of Oudet et al., ${ }^{31}$ who show that mandibular propulsion promotes condylar growth in the same direction. The combined treatment also increased the percentage of fibrillar collagens in this layer, suggesting that the effects on matrix deposition extended to the superior regions of the cartilage and could improve condylar growth. 
The expression of collagen III (reticular fiber) increases during connective tissue repair. ${ }^{32}$ In the condylar cartilage, collagen III is resynthesized, together with type II collagen, during cartilage repair. ${ }^{33}$ In this study, all the treatments increased collagen III, suggesting that as PBM as MA are able to stimulate condylar cartilage remodeling.

The widely accepeted PBM mechanism of action is the absorption of the LED/laser by the Citochrome C Oxidase enzyme of the respiratory chain in the internal mitochondrial membrane. As result, the ATP production and the cellular activity increase. ${ }^{19}$ In the bone, PBM increases osteoblasts and osteoclasts activity, ${ }^{10}$ osteoblasts viability, ${ }^{11}$ and extracellular matriz gene expression ${ }^{26}$ indicating that PBM favors bone formation. In the condylar cartilage, PBM has shown opposite effects as increased cartilage area ${ }^{34}$ and no changes in the cartilage thickeness. ${ }^{29}$

There are distinct protocols using different laser doses in studies involving mandibular condyle and it is well known that cells' behavior depends on irradiation conditions. ${ }^{35,36}$ We applied $0.4 \mathrm{~J} /$ point and a total dose of $3.2 \mathrm{~J}$ in the treatment and observed a reduction in the cartilage thickness. Cephalometric studies show that $5.0 \mathrm{~J} /$ point $^{37}$ results in higher condylar growth compared to $0.4 \mathrm{~J} /$ point of our study. On the contrary, the cartilage area increases after irradiation of $6.0 \mathrm{~J} / \mathrm{cm}^{2}$ (Total Energy applied of $7.9 \mathrm{~J}$ ). ${ }^{38}$ Possibly higher energy/point could have an important influence in the effect of PBM on cartilage. So, studies testing different laser parameters are important to discover the best parameter for condylar cartilage growth. Also, understanding the molecular basis that regulates condylar cartilage response to PBM could contribute to learning about the controversial behavior of the cartilage.

Clastic cells such as osteoclasts and chondroclasts resorb bone and mineralized cartilage during endochondral ossification. ${ }^{39}$ We showed that the number of clastic cells was similar among the groups, suggesting that the treatments did not affect the recruitment of clastic cells and none of the treatments accelerated cartilage absorption.

In conclusion, isolated PBM or MA increased condylar cartilage thickness possibly by increasing collagen and proteoglycan deposition in the maturation zone. According to the parameters used in this study, we were not able to show synergistic effect between the treatments. Additional studies testing different PBM parameters should be conducted to evaluate the possible synergistic effect between $\mathrm{PBM}$ and MA in the mandibular condyle.

\section{Author Disclosure Statement}

No competing financial interests exist.

\section{Funding Information}

This article was supported by a grant from the Goiás Research Foundation, Procs. (FAPEG No. 05/2012).

\section{Supplementary Material}

Supplementary Table S1

Supplementary Table S2

Supplementary Table S3

Supplementary Table S4

\section{References}

1. McNamara JA Jr., Seligman DA, Okeson JP. Occlusion, orthodontic treatment and temporomandibular disroders: a review. J Orofac Pain 1995;9:73-90.

2. Pacha MM, Fleming PS, Johal A. A comparison of the efficacy of fixed versus removable functional appliances in children with Class II malocclusion: a systematic review. Eur J Orthod 2016;38:621-630.

3. McNamara JA, Jr., Hinton RJ, Hoffman DL. Histologic analysis of temporomandibular joint adaptation to protrusive function in young adult rhesus monkeys (Macaca mulatta). Am J Orthod 1982;82:288-298.

4. Rabie AB, She TT, Hagg U. Functional appliance therapy accelerates and enhances condylar growth. Am J Orthod Dentofacial Orthop 2003;123:40-48.

5. McNamara JA, Jr., Carlson DS. Quantitative analysis of temporomandibular joint adaptations to protrusive function. Am J Orthod 1979;76:593-611.

6. Hajjar D, Santos MF, Kimura ET. Propulsive appliance stimulates the synthesis of insulin-like growth factors I and II in the mandibular condylar cartilage of young rats. Arch Oral Biol 2003;48:635-642.

7. Marques MR, Hajjar D, Franchini KG, Moriscot AS, Santos MF. Mandibular appliance modulates condylar growth through integrins. J Dent Res 2008;87:153-158.

8. Rabie AB, Xiong H, Hagg U. Forward mandibular positioning enhances condylar adaptation in adult rats. Eur $\mathrm{J}$ Orthod 2004;26:353-358.

9. Wu MJ, Zhan J, Gu ZY. Time course of expression of bcl-2 and bax in rabbit condylar chondrocytes following forward mandibular positioning. Angle Orthod 2008;78:453-459.

10. Seifi M, Maghzi A, Gutknecht N, Mir M, Asna-Ashari M. The effect of $904 \mathrm{~nm}$ low level laser on condylar growth in rats. Lasers Med Sci 2010;25:61-65.

11. Zancanela DC, Primo FL, Rosa AL, Ciancaglini P, Tedesco AC. The effect of photosensitizer drugs and light stimulation on osteoblast growth. Photomed Laser Surg 2011;29: 699-705.

12. Bello-Silva MS, de Freitas PM, Aranha AC, Lage-Marques JL, Simoes A, de Paula Eduardo C. Low- and high-intensity lasers in the treatment of herpes simplex virus 1 infection. Photomed Laser Surg 2010;28:135-139.

13. Javed F, Kellesarian SV, Romanos GE. Role of diode lasers in oro-facial pain management. J Biol Regul Homeost Agents 2017;31:153-155.

14. Walsh LJ. The current status of low level laser therapy in dentistry. Part 1. Soft tissue applications. Aust Dent J 1997; 42:247-254.

15. Bjordal JM, Couppe C, Chow RT, Tuner J, Ljunggren EA. A systematic review of low level laser therapy with location-specific doses for pain from chronic joint disorders. Aust J Physiother 2003;49:107-116.

16. de Paula Eduardo C, Aranha AC, Simoes A, et al. Laser treatment of recurrent herpes labialis: a literature review. Lasers Med Sci 2014;29:1517-1529.

17. Robijns J, Censabella S, Bulens P, Maes A, Mebis J. The use of low-level light therapy in supportive care for patients with breast cancer: review of the literature. Lasers Med Sci 2017;32:229-242.

18. Spanemberg JC, Figueiredo MA, Cherubini K, Salum FG. Low-level laser therapy: a review of its applications in the management of oral mucosal disorders. Altern Ther Health Med 2016;22:24-31. 
19. Karu T. Primary and secondary mechanisms of action of visible to near-IR radiation on cells. J Photochem Photobiol B 1999;49;1-17.

20. Spivak JM, Grande DA, Ben-Yishay A, Menche DS, Pitman MI. The effect of low-level Nd:YAG laser energy on adult articular cartilage in vitro. Arthroscopy 1992;8:36-43.

21. Shen G, Zhao Z, Kaluarachchi K, Bakr Rabie A. Expression of type $\mathrm{X}$ collagen and capillary endothelium in condylar cartilage during osteogenic transition-a comparison between adaptive remodelling and natural growth. Eur J Orthod 2006;28:210-216.

22. Kushibiki T, Tajiri T, Ninomiya Y, Awazu K. Chondrogenic mRNA expression in prechondrogenic cells after blue laser irradiation. J Photochem Photobiol B 2010;98:211215.

23. Weibel ER. Principles and methods for the morphometric study of the lung and other organs. Lab Invest 1963;12: 131-155.

24. Bates D, Maechler M, Bolker B, Walker S. Fitting linear mixed-effects models using lme4. J Stat Softw 2015;67: $1-48$.

25. Zuur AF, Ieno EN, Walker NJ, Saveliev AA, Smith GM. Mixed Effects Models and Extensions in Ecology with R. New York: Springer, 2009. ISBN-10:1441927646.

26. Hamajima S, Hiratsuka K, Kiyama-Kishikawa M, et al. Effect of low-level laser irradiation on osteoglycin gene expression in osteoblasts. Lasers Med Sci 2003;18:78-82.

27. Liu Y, Zhang H. Low-level laser irradiation precondition for cardiac regenerative therapy. Photomed Laser Surg 2016;34:572-579.

28. Fekrazad R, Eslaminejad MB, Shayan AM, et al. Effects of photobiomodulation and mesenchymal stem cells on articular cartilage defects in a rabbit model. Photomed Laser Surg 2016;34:543-549.

29. Abtahi M, Poosti M, Saghravanian N, Sadeghi K, Shafaee $\mathrm{H}$. The effect of low level laser on condylar growth during mandibular advancement in rabbits. Head Face Med 2012; 23;8:4.

30. Figueiredo ACR, dos Santos FCA, Capeletti LR, Galdino MVB, Araújo RV, Marques MR. Low level laser intensity improves propulsive appliance effects on condylar cartilage. In Proceedings Volume 8208, Lasers in Dentistry XVIII; 82080T 2012. Event: SPIE BiOS, San Francisco, CA, 2012.

31. Oudet C, Petrovic A, Stutzmann J. Time-dependent effects of a "functional"-type orthopedic appliance on the rat mandible growth. Chronobiol Int 1984;1:51-57.
32. Clore JN, Cohen IK, Diegelmann RF. Quantitation of collagen types I and III during wound healing in rat skin. Proc Soc Exp Biol Med 1979;161:337-340.

33. Salo LA, Raustia AM. Type II and type III collagen in mandibular condylar cartilage of patients with temporomandibular joint pathology. J Oral Maxillofac Surg 1995; 53:39-44; discussion 45.

34. El-Bialy T, Alhadlaq A, Felemban N, Yeung J, Ebrahim A, Hassan AH. The effect of light-emitting diode and laser on mandibular growth in rats. Angle Orthod 2015;85:233-238.

35. Borges RMM, Cardoso DS, Flores BC, et al. Effects of different photobiomodulation dosimetries on temporomandibular dysfunction: a randomized, double-blind, placebo-controlled clinical trial. Lasers Med Sci 2018; 33:1859-1866.

36. Karu TI, Pyatibrat LV, Kalendo GS, Esenaliev RO. Effects of monochromatic low-intensity light and laser irradiation on adhesion of HeLa cells in vitro. Lasers Surg Med 1996; 18:171-177.

37. Oksayan R, Sokucu O, Ucuncu N. The effects of low-level laser therapy on condylar growth with a mandibular advancement appliance in rats. Photomed Laser Surg 2015; 33:252-257.

38. Çırak E, Özyurt A, Peker T, Ömeroğlu S, Güngör MN. Comparative evaluation of various low-level laser therapies on bone healing following tooth extraction: an experimental animal study. J Craniomaxillofac 2018;46:11471152.

39. Arana-Chavez VE, Bradaschia-Correa V. Clastic cells: mineralized tissue resorption in health and disease. Int $\mathbf{J}$ Biochem Cell Biol 2009;4:446-450.

Address correspondence to: Mara Rubia Marques, PhD

Biological Sciences Institute

Department of Histology, Embryology and Cell Biology

Federal University of Goiás

Room 01

Goiânia 74690-900

Goiás

Brazil

E-mail: mrubia.01@hotmail.com

Received: February 22, 2019. Accepted after revision: July 24, 2019. Published online: December 17, 2019. 